\title{
Seismic Isolation of Reactor Assembly for a Fixed Base Accelerator Driven System Reactor Building
}

\author{
Bong Yoo and Didier De Bruyn \\ Primary System Design Group, SCK-CEN, Belgium Nuclear Research Center, Mol 2400, Belgium
}

\begin{abstract}
In the SILER (Seismic-Initiated events risk mitigation in LEad-cooled Reactors) Project, it is interesting to apply seismic isolation technology for the reactor assembly of the fixed base reactor building for ADS (Acceleration Driven System) heavy liquid reactor MYRRHA (Multipurpose Hybrid Research Reactor for High-Tech Application) which contains the most critical safety related components, such as reactor vessel, safe shutdown and control rod mechanisms, primary heat exchangers, primary pumps, spallation target assembly and fuel assemblies, etc. The purpose of this paper is to investigate the possibility of an application of a partial seismic isolation to the safety critical components only, here, the reactor assembly. This paper presents the preliminary analysis results of the isolated reactor assembly and compares these with those of seismic isolated ADS reactor building. The analysis results show the reduction of the seismic acceleration response but the increase of the relative displacement for the reactor assembly. Some safety issues, especially, coolant's incapable covering the reactor core make difficult to apply for the partial seismic isolation of the ADS reactor assembly due to large relative displacement occurring the partial isolation system. Further study on the partial seismic isolation application of the critical safety components are also discussed.
\end{abstract}

Key words: Partial seismic isolation, ADS MYRRHA reactor building, reactor assembly, interface systems, FRS (floor response spectra), reduction of accelerations, increase of relative displacement, reactor safety issues.

\section{Introduction}

The purpose of this paper is to investigate the possibility of an application of partial SI (seismic isolation) to the RA (reactor assembly) and to identify the reactor safety issues.

Some works and development of SI systems and SI guidelines for nuclear power plants [1,2] have been done using horizontal SI system for whole RB (reactor building) and entire horizontal SI with partial vertical component SI, but there is few study to apply a partial horizontal SI for the safety critical components with fixed base RB in nuclear fields.

Advantages with partial SI application for RA with a fixed base ADS (Acceleration Driven System) RB are foreseen in:

- less seismic core compaction;

- favorable neutronics behavior;

- marginable seismic safe shutdown capability;

Corresponding author: Bong Yoo, Ph.D., research fields: mechanical and structural development in nuclear reactors.
- much lower seismic load on the RV (reactor vessel), spallation target assembly with beam tube and other reactor internals.

The partial SI of the RA enables to achieve the economic design by reducing the number of isolators, while it would have the same advantages as the SI of the whole $\mathrm{RB}$ in reducing the acceleration responses for the RA.

Based on designs of isolators and isolation arrangement for the SI of the RA, simple seismic response calculations are performed using the input motions given at the RV support of the fixed base RB. The seismic responses are obtained as the maximum relative displacement between the isolated RA and non-isolated reactor pit and ZPA (zero period acceleration) at the RA for the DBE (design basis earthquake) and the BDBE (beyond-design basis earthquake) cases.

Comparison of the seismic responses is made between RA SI and RB SI, and variation of HDRB 
(high damping rubber bearing) damping and isolation frequencies of RA SI system.

Some safety issues caused by the RA SI are also discussed, such as RVAC (reactor vessel auxiliary cooling) system with the large seismic gap and too many flexible joints above the reactor cover due to large relative displacement between the RA and the reactor pit. Sloshing of the isolated RA and its effect on the reactor internals are another safety concerns and are to be handled separately from this paper.

\section{SI (Seismic Isolation) Approach for ADS}

\section{(Acceleration Driven System) Reactor} Assembly

The approach used for the seismic isolation of the RA can be described as follows:

- Input motions in acceleration time histories at RV support are defined through the time history analysis of the fixed base RB;
- Design of isolator and arrangement of SI system for RA should be made;

- Modeling of isolation system is simplified using 2-DOF (degree of freedom) lumped-mass spring damper system including RA as a lumped mass since the RA can be assumed to behave as a rigid body motion.

Then a linear theory of seismic isolation [3], using the spectral values at the RV support of the fixed base $\mathrm{RB}$ as input motions, has been carried out to calculate the seismic responses for the isolated ADS reactor assembly.

\subsection{ADS (Acceleration Driven System) Reactor Building}

The RB made of reinforced concrete has the dimension of $90 \mathrm{~m}$ (length) $\times 49 \mathrm{~m}$ (width) $\times 65 \mathrm{~m}$ (height) ( $-26.5 \mathrm{~m}$ below grade) and its total mass is 223,000 t. Fig. 1 shows the section view of the fixed base ADS RB and the RA [4].

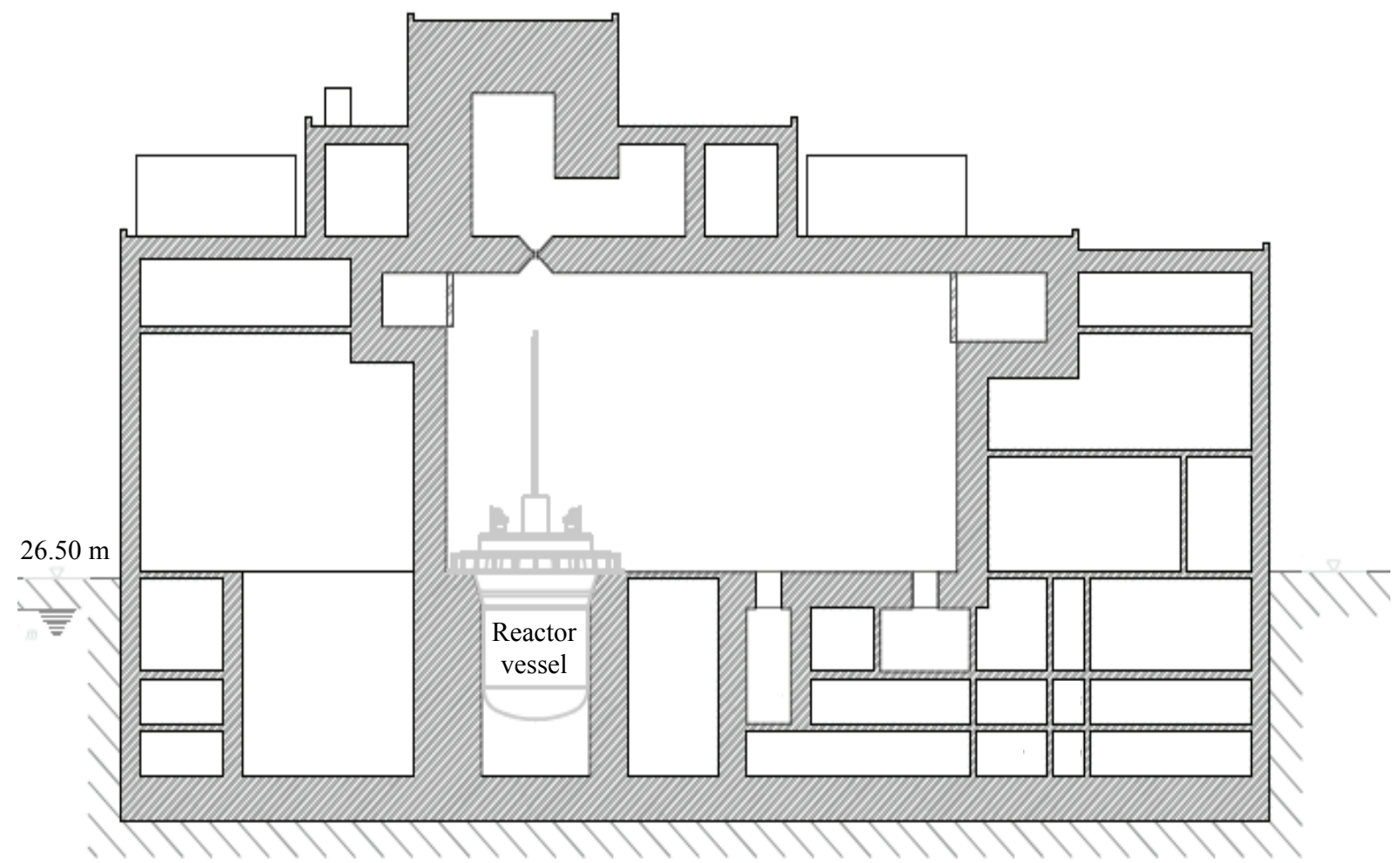

Fig. 1 ADS MYRRHA reactor building cross section $90 \mathrm{~m}$ (length) $\times 49 \mathrm{~m}$ (width) $\times 65 \mathrm{~m}$ (height) $(-26.5 \mathrm{~m}$ below grade) 


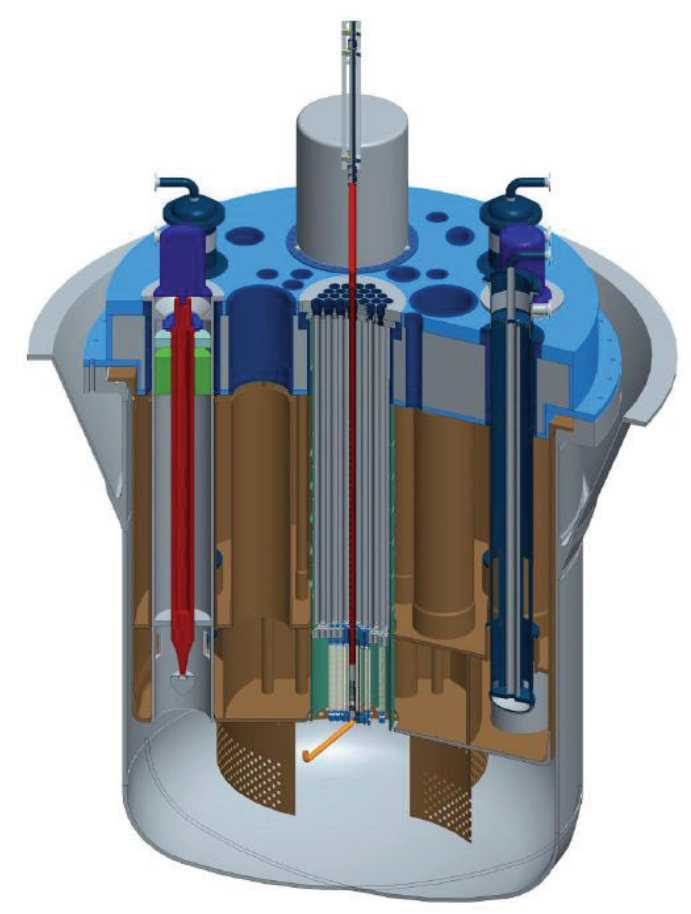

Fig. 2 ADS MYRRHA reactor assembly (Revision 1.2).

\subsection{Reactor Assembly}

The 100 MWth ADS RA made of SS316L has the cylindrical dimension of $8.03 \mathrm{~m}$ (inner diameter) $\times$ $80 \mathrm{~mm}$ (thickness) $\times 13.5 \mathrm{~m}$ (height). The total mass of RA is 5,700 $\mathrm{t}$ including the mass of the LBE (Lead
Bismuth Eutectic) coolant, 4,350 t.

It consists of $\mathrm{RV}$, reactor cover, reactor internal components, such as two primary heat exchangers, four primary pumps, 151 core positions for fuel assemblies and dummies, six CRs (control rods) and three SRs (shutdown rods) mechanisms, spallation target assembly with beam tube, two fuel handling mechanisms, connecting pipes and diaphragm. Fig. 2 shows the Revision 1.2 of reactor assembly [5].

\subsection{Interface Systems}

To define the relative displacement and acceleration response at the interfaces between isolated RA and non-isolated parts, the connecting systems and pipings on reactor cover have been identified as shown in Table 1 and Fig. 3.

The typical connecting systems above reactor cover are as follows:

- RVAC pipings: four groups of 40 pipings;

- beam tube/spallation target assembly;

- pipings: LBE conditioning system, cover gas conditioning system, pressure relief system;

- cables connections: CR/SR mechanisms, fuel handling mechanisms, pumps, etc.

Table 1 Interconnection systems for reactor assembly isolation.

\begin{tabular}{|c|c|c|c|c|}
\hline No. & Isolated & Non-isolated & Size & Remarks \\
\hline 1 & Spallation target (1) & Beam tube & $\begin{array}{l}\text { OD (outer diameter) } \sim 88 \mathrm{~mm} \text {, } \\
\text { thickness: } 1.375\end{array}$ & $\begin{array}{l}\text { Vacuum, } 450 \sim 500{ }^{\circ} \mathrm{C} \\
* \text { T91/SS316L }\end{array}$ \\
\hline 2 & Si-doping channel (2) & $\begin{array}{l}\text { Piping, ducts, electrical } \\
\text { cables and trays }\end{array}$ & $\begin{array}{l}\text { OD1010, box type duct } \\
\text { *thickness: } 4.78\end{array}$ & $\begin{array}{l}* 10 \text { bar gage, } 80{ }^{\circ} \mathrm{C} \\
\text { SS316L }\end{array}$ \\
\hline 3 & PHX(4) & $\begin{array}{l}\text { Pipings for feed water } \\
\text { and steam lines }\end{array}$ & $\begin{array}{l}\text { OD200 (feed water) } \\
\text { OD510 (steam lines) }\end{array}$ & $\begin{array}{l}29 \text { bar gage, } 230^{\circ} \mathrm{C} \\
16 \text { bar gage, } 200^{\circ} \mathrm{C}, \mathrm{SS} 316 \mathrm{~L}\end{array}$ \\
\hline 4 & Pump (2) & Electrical cables & - & No outlet pipings \\
\hline 5 & IVFHM (2) & Flex electrical cables & - & No connecting pipes \\
\hline 6 & $\begin{array}{l}\text { LBE-conditioning } \\
\text { inlet (2)/outlet (2) }\end{array}$ & Pipings & $\begin{array}{l}\text { OD300 (outlet), elliptical } \\
\text { OD100 (inlet) }\end{array}$ & $\begin{array}{l}20 \text { bar gage, } 350^{\circ} \mathrm{C} \\
12 \text { bar gage, } 550{ }^{\circ} \mathrm{C}, \mathrm{SS} 316 \mathrm{~L}\end{array}$ \\
\hline 7 & $\begin{array}{l}\text { Cover gas conditioning system } \\
\text { inlet (2)/outlet (2) }\end{array}$ & Pipings & OD300 (out/inlet) & $\begin{array}{l}6 \text { bar gage, } 350{ }^{\circ} \mathrm{C} \text { or } \\
1 \text { bar gage, } 5500^{\circ} \mathrm{C}, \mathrm{SS} 316 \mathrm{~L}\end{array}$ \\
\hline 8 & Fuel transfer channel (2) & Flex inter tubes & OD420 & SS316L \\
\hline 9 & Wet-sipping device (2) & Flex inter tubes & OD300 & SS316L \\
\hline 10 & Pressure relief system (2) & - & OD600 & 6 bar gage, $550^{\circ} \mathrm{C}, \mathrm{SS} 316 \mathrm{~L}$ \\
\hline 11 & Above core structure (2) & $\begin{array}{l}\text { IPS cables (isotope rabbit } \\
\text { system) }\end{array}$ & - & No connecting pipes \\
\hline 12 & $\mathrm{CR} / \mathrm{SR} / \mathrm{IPS}$ & Flex electrical cables & - & No connecting pipes \\
\hline 13 & RVAC 4 piping groups & 160 pipes $(40 \times 4=160)$ & OD110, *thickness: 7.11 & $\begin{array}{l}\text { RV support, } \\
\text { SS316 or } 304\end{array}$ \\
\hline
\end{tabular}

\footnotetext{
* means "assumed".
} 


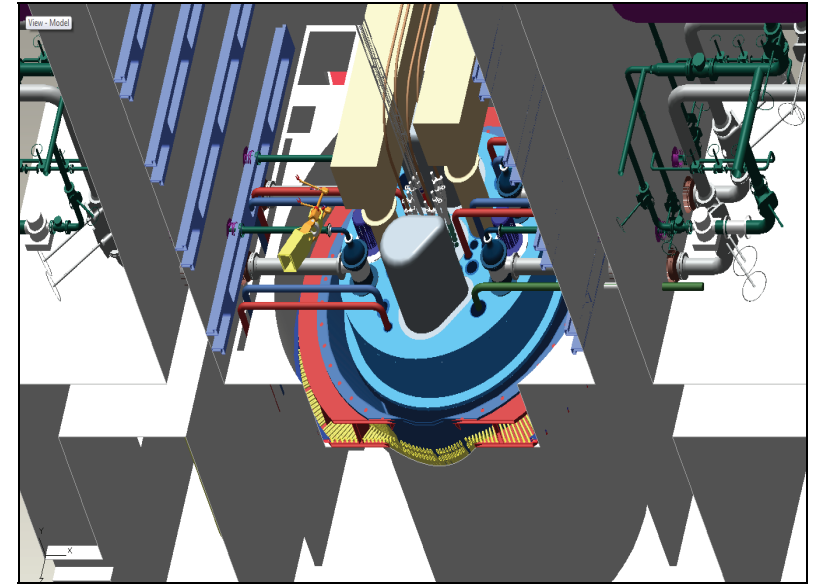

Fig. 3 Interconnection systems for reactor assembly. Horizontal elastic response spectra ( $5 \%$ hard soil) for DBE (design basis earthquake)

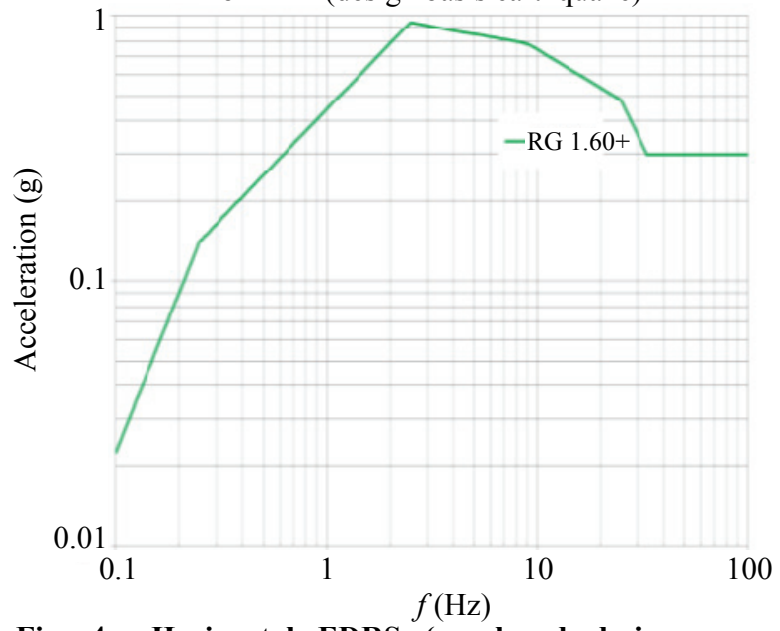

Fig. 4 Horizontal EDRS (enveloped design response spectra) for DBE for ADS MYRRHA.

To keep the seismically isolated RA to be rigid motion during the strong earthquakes, a seismic free gap induced by the relative displacement should be determined and a fail-safe system and a gap joint cover around the RA should be designed to take into account an additional $50-\mathrm{cm}$ space for the installation of the RVAC pipings.

\section{Seismic Responses for RA (Reactor Assembly) SI (Seismic Isolation)}

\subsection{Input Motions}

The ZPAs of the EDRS (enveloped design response spectra) are $0.3 \mathrm{~g}$ for the $\mathrm{DBE}$ and $0.9 \mathrm{~g}$ for the BDBE in horizontal direction, respectively, and Fig. 4 typically shows a horizontal EDRS for the fixed base ADS RB [6].

The FRS (floor response spectra) at RV support for DBE and BDBE conditions calculated through soil structure interaction analysis for the fixed base RB [7] are used as input motions for the RA SI and are typically shown in horizontal $x$-direction in Fig. 5.

Referring to the analysis results, the frequencies of the fixed base RB on a multilayered soft site specific soil are shifted to lower as:

- horizontal frequencies ( $x$ - and $y$-direction): $3.6 \sim 4.6 \mathrm{~Hz} / 1.1 \sim 1.4 \mathrm{~Hz}$;

- vertical frequency: $8.8 \mathrm{~Hz} / 2.5 \mathrm{~Hz}$.

3.2 Design of Isolator and Isolator Arrangement for Reactor Assembly SI (Seismic Isolation)

For the design of seismic isolator for the RA SI, the

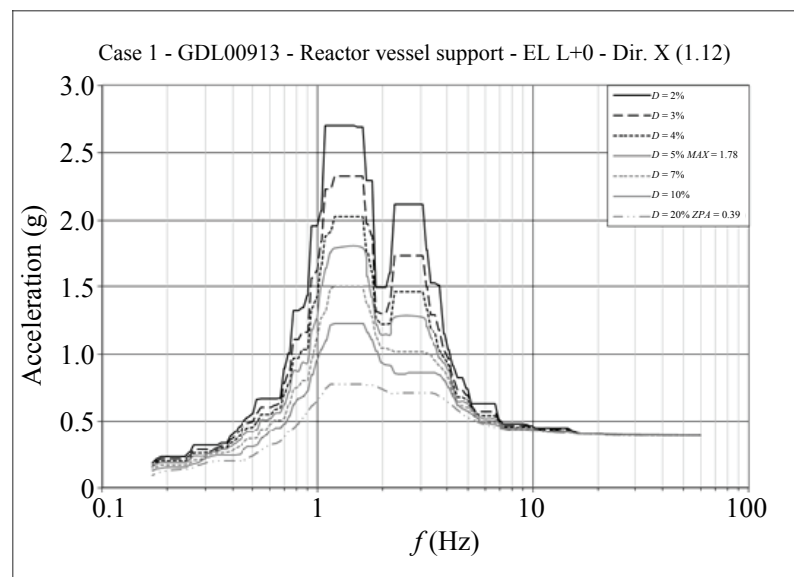

(a)

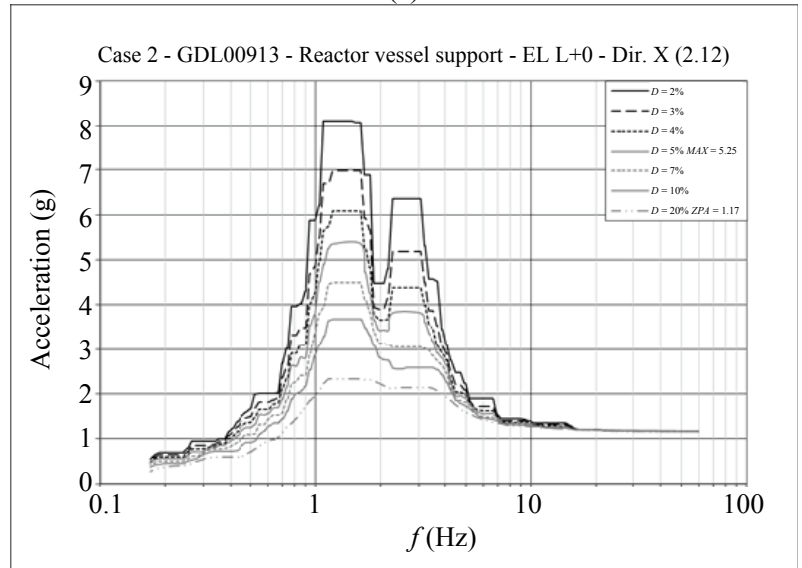

(b)

Fig. 5 FRS at RV support subjected to: (a) DBE for ADS MYRRHA; (b) BDBE for ADS MYRRHA. 
HDRB SI-H1050/290 as shown in Fig. 6 is chosen from the FIP industriale catalogue [8].

The characteristics of the isolator are as follows:

- diameter $1.05 \mathrm{~m} \times$ total rubber thickness $290 \mathrm{~mm}$;

- rubber shear modulus $G=1.4 \mathrm{MPa}$;

- max vertical load: $15,100 \mathrm{kN}$;

- horizontal stiffness: $4.18 \mathrm{kN} / \mathrm{mm}$;

- horizontal damping: $10 \%$;

- vertical stiffness: $4,229 \mathrm{kN} / \mathrm{mm}$;

- vertical damping (assumed): $4 \%$.

Typical hysteretic curve of an elastomeric isolator achieved during dynamic tests as shown in Fig. 7 gives decreasing stiffness and equivalent damping ratio with increasing shear strain amplitude, as shown in Figs. 8 and 9. It is assumed that the stiffness and damping ratio are used as constants for the simplicity.

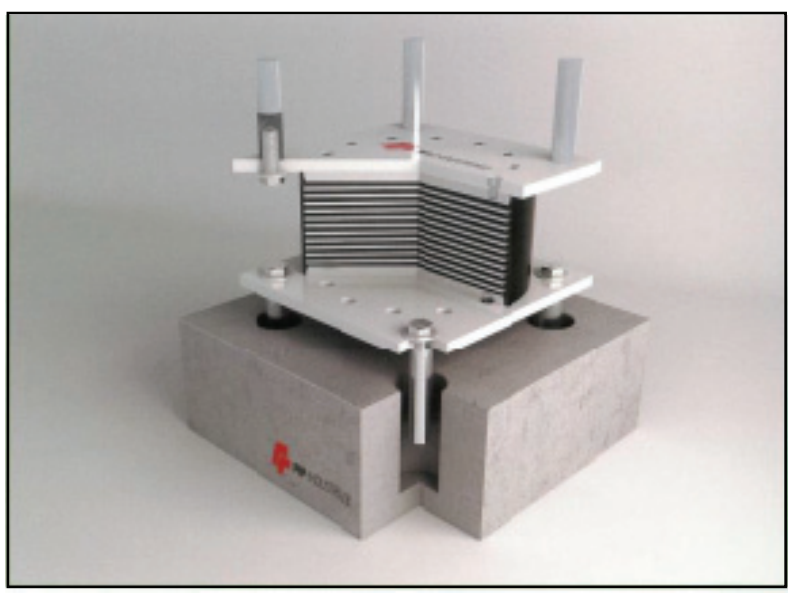

Fig. 6 HDRB (courtesy of FIP industriale).

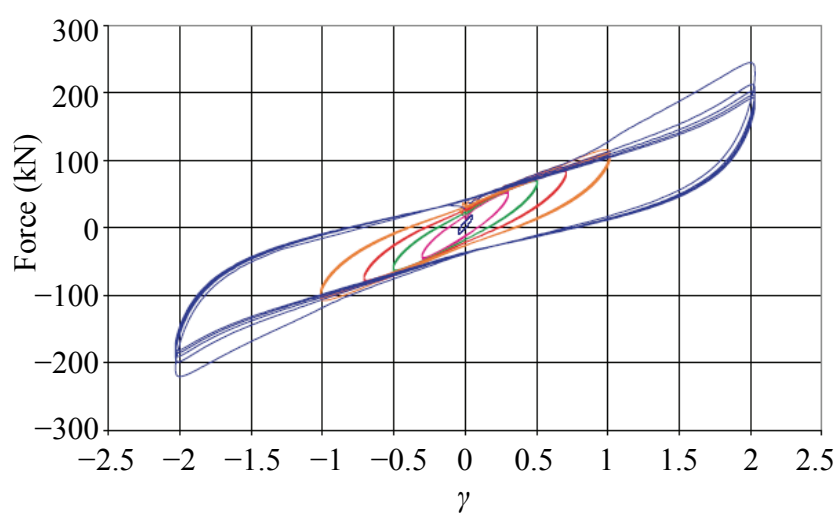

Fig. 7 Dynamic chacteristics of HDRB.
For the arrangement of the isolators under the RV support considering the mass of the RA, the isolation frequency should be determined from the given FRS. The isolation frequency of RA is preliminary chosen to be $0.5 \mathrm{~Hz}$, with which a spectral acceleration value from the FRS with $10 \%$ damping ratio is reasonably selected as $0.3 \mathrm{~g}$ for the DBE case for the seismic design for the isolated RA.

With 12 HDRBs, the isolation frequency of the RA is calculated as $0.47 \mathrm{~Hz}$. Each isolator can be arranged in every $30^{\circ}$ (about $3 \mathrm{~m}$ ) apart under the RV support.

\subsection{Seismic Responses of RA (Reactor Assembly) SI} (Seismic Isolation)

A simple linear theory of base isolation using 2-DOF system with linear spring and linear viscous damping modeled for HDRB isolation system provides

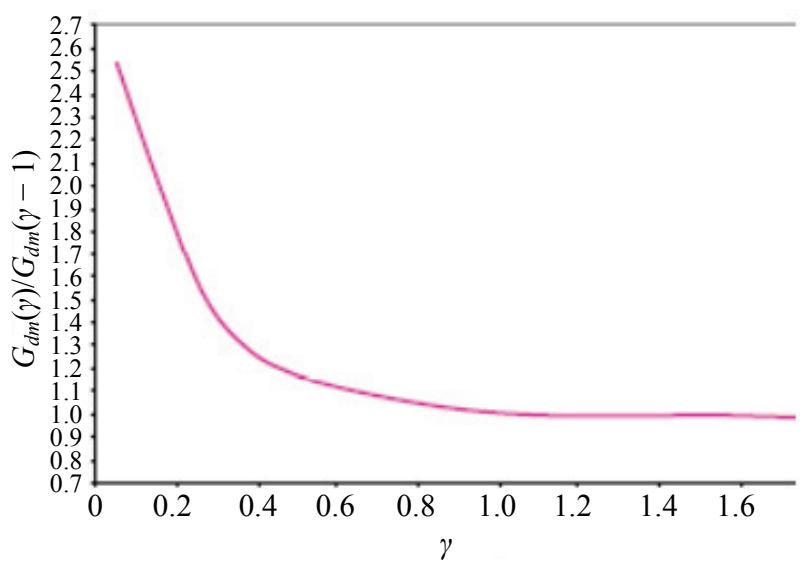

Fig. 8 Mean variation in dynamic shear modulus $\left(G_{d m}\right)$ as a function of shear strain $(\gamma)$.

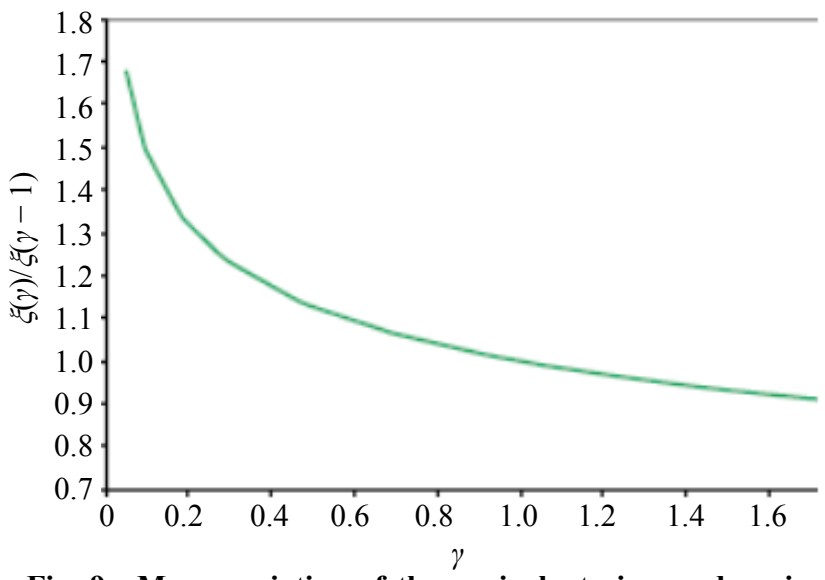

Fig. 9 Mean variation of the equivalent viscous damping coefficient $\xi$ as a function of shear strain $\gamma$. 
the seismic responses [3], relative displacements between isolated and non-isolated structures and accelerations in following forms:

- Relative displacement at isolated base is:

$$
\begin{gathered}
\left|V_{b}\right|_{\max }=S A\left(\omega_{b}{ }^{*}, \beta_{b}{ }^{*}\right) / \omega_{b} \times 2, \\
\varepsilon=\left(\omega_{b} / \omega_{s}\right)^{2}, \quad \omega_{b}=\sqrt{k_{b} / M}=\omega_{b}{ }^{*}, \\
\omega_{s}=\sqrt{k_{s} / m}=\sqrt{\omega_{s} /(1-\gamma)}
\end{gathered}
$$

where, $\omega_{b}$ is isolated frequency, $\omega_{s}$ is structural frequency, $k_{b}$ is stiffness of isolation system, $k_{s}$ is stiffness of structure, total mass $M=m+m_{b}, m$ is structure mass and $m_{b}$ is isolated base mass, mass ratio $\gamma=m / M$

- The base shear coefficient $C_{s}$ is given by:

$$
C_{s}=\left|k_{s} \cdot V_{s} / m\right|=S A\left(\omega_{b}, \beta_{b}\right) \sqrt{1+(1-\gamma) \varepsilon}
$$

where, the second term is negligible;

- The reduction in base shear between isolated structure and fixed one is given as:

$$
R F \text { (reduction factor) }=S A\left(\omega_{b}, \beta_{b}\right) / S A\left(\omega_{s}, \beta_{s}\right)
$$

For the isolation of the ADS RA using $\varepsilon=\left(\omega_{b} / \omega_{s}\right)^{2}$ $=(0.47 / 3.71)^{2}=0.016$, and $\gamma=m_{s} / M=0.975$, the seismic responses are calculated with varying SI frequency from $0.47 \mathrm{~Hz}$ to $0.8 \mathrm{~Hz}$ and HDRB damping ratio from $7 \%$ to $20 \%$. The relative displacement and the acceleration seismic responses calculated are shown in Figs. 10-12. Noting that the $V_{s}$ is negligible, which means the isolated structure behaves in a rigid way.

In order to reduce the relative displacement for the SI of RA, isolation frequency and damping should be increased as shown in Figs. 10-12: Optimal isolation frequency is $0.7 \mathrm{~Hz}$ and the relative displacements are $24 \mathrm{~cm}$ with $10 \%$ damping of HDRB and $17 \mathrm{~cm}$ with $20 \%$ damping, but increasing accelerations.

With the seismic isolation frequency of $0.47 \mathrm{~Hz}$, the maximum relative displacement and ZPA of the isolated structure are calculated as $34.2 \mathrm{~cm}$ and $0.3 \mathrm{~g}$, respectively. The reduction factor of acceleration for HDRB SI of the RA system becomes 1/3 1/5 depending on the directions.

The equivalent shear strain in HDRB to the maximum relative displacement $34.2 \mathrm{~cm}$ for the SI of RA is $118 \%$ which exceeds the tentative strain design requirement of $100 \%$ in DBE condition.

Therefore, SI frequency would be $0.7 \mathrm{~Hz}$ which gives the relative displacement less to be $24 \mathrm{~cm}$ equivalent to $83 \%$ shear strain in HDRB but adversely makes larger ZPA to be $0.48 \mathrm{~g}$.

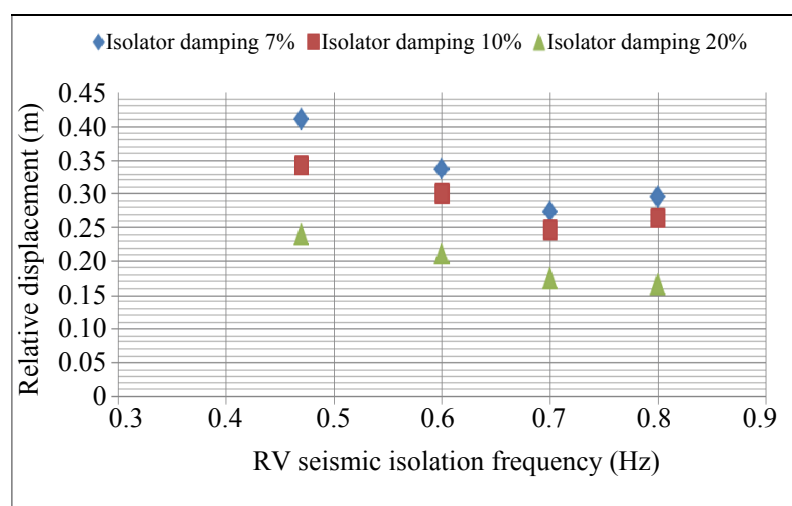

Fig. 10 Relative displacement depending on isolation frequency of reactor assembly for DBE.

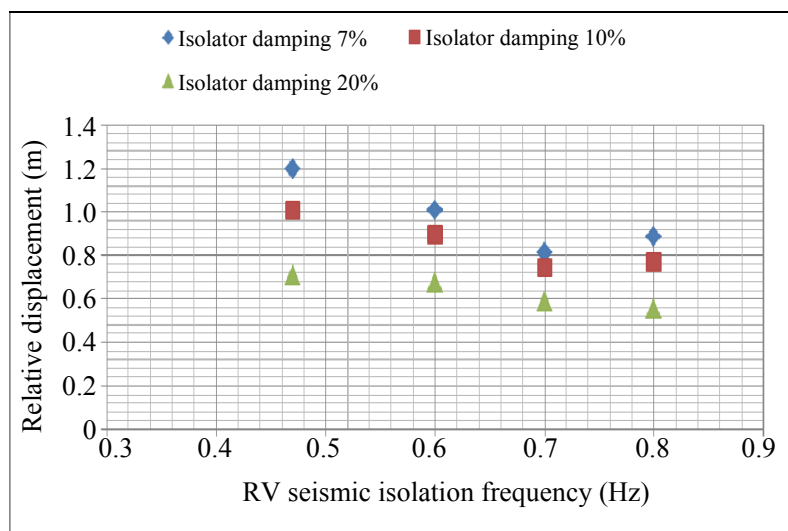

Fig. 11 Relative displacement depending on isolation frequency of reactor assembly for BDBE.

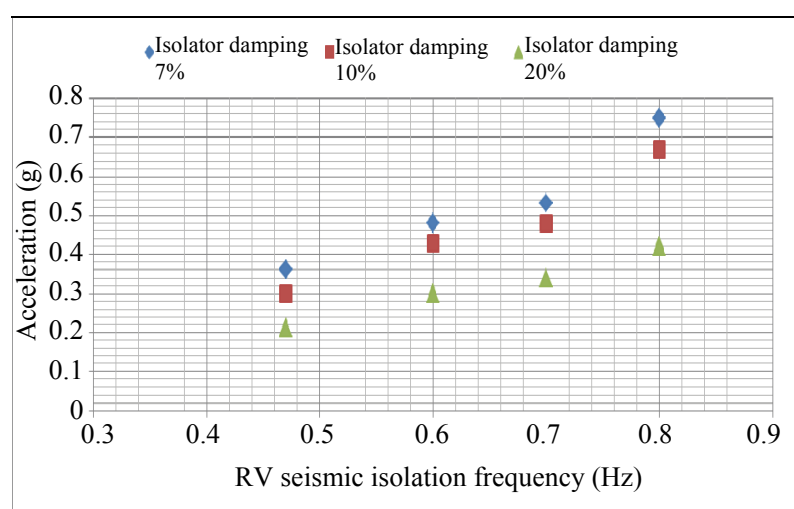

Fig. 12 Accelerations depending on isolation frequency of reactor assembly for $\mathrm{DBE}$. 
It is noted that for whole SI of RB using the same isolation frequency $0.47 \mathrm{~Hz}$, the relative displacements at the isolators are $26 \mathrm{~cm}(90 \%$ shear strain) for DBE and $78 \mathrm{~cm}$ (269\% shear strain) for BDBE, and the horizontal ZPA at the RA are $0.2 \mathrm{~g}$ for DBE and 0.6g for BDBE [7], respectively. However the ZPA in vertical direction with RA SI are amplified to be $0.45 \mathrm{~g}$ for $\mathrm{DBE}$ and $1.35 \mathrm{~g}$ for BDBE, respectively.

\subsection{Some Issues on RA (Reactor Assembly) SI (Seismic Isolation)}

Large seismic gap with RA SI causes to design interconnection systems above reactor cover with very complex flexible joints, to increase size of containment boundary and to meet safety requirement of cooling of ADS reactor difficult in severe accidents. Should leakage of LBE inventory to reactor pit due to $\mathrm{RV}$ failure event, it needs to cover reactor core with LBE coolant to keep natural circulation, as well as to cool RV by RVAC system. The cooling gap for the RVAC system is designed to be $50 \mathrm{~cm}$. The total seismic gap of $84.2 \mathrm{~cm}$ for DBE and of $150 \mathrm{~cm}$ for BDBE including $50 \mathrm{~cm}$ gap for RVAC system would make the LBE coverage of the reactor core cooling unlikely.

It would be also difficult to repair and maintain isolators inside containment boundary due to uneasy accessibility. Another concern is how to verify the effect of irradiation on isolators.

A fail-safe system and a gap joint cover around the reactor pit could be designed by using a moat system to reduce the seismic impact on the RA and to prevent from debris falling into the pit.

\section{Conclusions}

Seismic isolation frequency of the ADS RA is determined to be $0.47 \mathrm{~Hz}$ and isolators are accordingly designeed using HDRB.

Relative displacement between isolated RA and reactor pit has been calculated by a mode superposition method using FRS at RV support for fixed base ADS RB as input motions:

- Max displacement is $0.34 \mathrm{~m}$, equivalent to isolator strain $118 \%$ for $10 \%$ HDRB for DBE;

- Max displacement is $1.0 \mathrm{~m}$ for $10 \%$ HDRB for BDBE.

The ZPA of SI for ADS RV with isolation frequency of $0.47 \mathrm{~Hz}$ are:

- $0.3 \mathrm{~g}$ for $10 \% \mathrm{HDRB}$ for DBE;

- $0.88 \mathrm{~g}$ for $10 \%$ HDRB for BDBE.

The isolation frequency of the RA is suggested to be $0.7 \mathrm{~Hz}$ to reduce the relative displacement as $24 \mathrm{~cm}$ and resulting in isolator strain to be $83 \%$, and adversely amplifying ZPA from $0.3 \mathrm{~g}$ to $0.48 \mathrm{~g}$.

Comparison of the seismic responses of the ADS RA between current SI of RA only with fixed RB using 2-DOF simple linear SI analysis and SI of RB using FEM analysis shows good agreement in the relative displacements as $34.2 \mathrm{~cm} / 26 \mathrm{~cm}$, and in the $\mathrm{ZPA}$ as $0.3 \mathrm{~g} / 0.2 \mathrm{~g}$, respectively for DBE.

The additional seismic gap induced by an application of SI for the ADS RA to the cooling gap would not meet the safety requirement of the LBE coolant coverage of reactor core and the cooling of the $\mathrm{RV}$ in case of a failure of the RV.

Therefore, the SI of RA with fixed base RB should not be recommended due to incompliance to meet the safety cooling requirement, instead the SI of whole $\mathrm{RB}$ is strongly recommended for the ADS MYRRHA.

Another issues raised above should be investigated further. It would be necessary to further study on vertical RA SI or 3D SI of RB which enables to reduce vertical seismic responses. It has been recognized that the application for $2 \mathrm{D}$ horizontal seismic isolation systems inherently induces the amplification of the vertical seismic acceleration responses, especially on hard rock.

\section{Acknowledgments}

The authors warmly thank the European Commission for the financial support to the SILER 
Project in its 7th FP (Framework Programme).

\section{References}

[1] IAEA (International Atomic Energy Agency). 2002. Verification of Analysis Methods for Predicting the Behaviour of Seismically Isolated Nuclear Structures. IAEA-TECDOC-1288. Final report of a co-ordinated research project 1996 1999.

[2] RCC-CW Standard. 2014. French Experience and Practice of Seismically Isolated Nuclear Facilities. AFCEN-CR-RG-2014-02-18-1. Paris: RCC-CW Standard, AFCEN.

[3] Kelly, J. M. 1997. Earthquake-Resistant Design with Rubber. New York: Springer.

[4] De Bruyn, D., Yoo, B., Forni, M., Pogianti, A., De Grande, S., Castellano, M. G., et al. 2013. "Seismic-Initiated Events Risk Mitigation in Lead-Cooled Reactor Mid-term Evaluation of the Results of the FP7 SILER Project." Presented at International Congress on Advances in Nuclear Power Plants (ICAPP'13), Jeju, Korea.
[5] De Bruyn, D., Fernandez, R., Mansani, I., Woaye-Hune, A., Sarotto, M., and Bubelis, E. 2012. "The Fast-Spectrum Transmutation Experimental Facility FASTEF: Main Design Achievements (Part 1 : Core and Primary System) within The FP7-CDT Collaborative Project of the European Commission." Presented at 2012 International Congress on Advances in Nuclear Power Plants (ICAPP'12), Chicago, Illinois, USA.

[6] EA (Empresarios Agrupados) International. 2012. Description of Systems: ADS. Document No. 092-260-F-C-00102. Deliverable D2.1, Part B of the SILER Project. Madrid: EA (Empresarios Agrupados) International.

[7] EA (Empresarios Agrupados) International. 2012. Description of the Models of the Reactor Systems, Description of the Computational Models of the ADS Reactor System. Document No. 092-260-F-C-00103. Deliverable D2.3, Part B of the SILER Project. Madrid: EA (Empresarios Agrupados) International.

[8] Dusi, A. 2012. "Task 2.3 Design and Modelling of Seismic Isolators for MYRRHA." Presented at First Annual Technical Meeting, Bologna, Italy. 